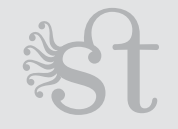

\title{
Carta de Norbert Wiener a sua irmã Bertha sobre o encontro com Einstein
}

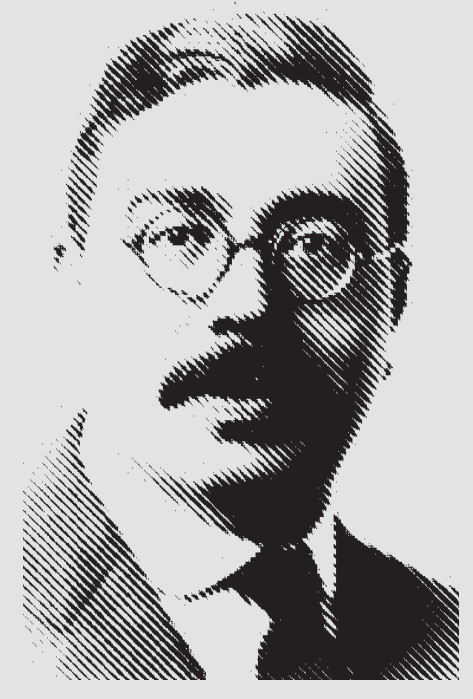

Grenoble, 27 de julho de 1925 .

Querida Bertha, ${ }^{\mathbf{1}}$

Apresentei meu trabalho hoje, parcialmente em inglês e parcialmente em mau francês. Ele não teve qualquer efeito; só estavam cinco pessoas na audiência, nenhum deles de análise, e só um deles de relevância matemática. Era Cartan. ${ }^{2}$ Quando fui apresentado a ele como Mr. Wiener, ele disse “Não, Norbert Wiener?”. Eu lhe conto, garota!

Meu francês está abaixo da linha d'água. Nas últimas quatro semanas, adquiri o hábito de pensar em alemão e agora, de vez em quando, fico com as linhas cruzadas. Logo estarei recuperado, sem fazer mais confusões. Mas estou terrivelmente cansado da viagem de volta de Leipzig - as últimas 24 horas sem repousar - e imagino que esse tipo de dificuldade seria esperado. 
Sábado à tarde, ${ }^{3}$ saí para uma caminhada com $\mathrm{L}^{4}$ e um grupo de professores de Leipzig. Koebe 5 de Iena também estava lá. Contam uma história sobre ele - e ele conta a mesma história sobre si próprio - que enquanto admirava o famoso teto da Capela Sistina em Roma comentou: "essas pinturas um dia perecerão, mas meu trabalho sobre a teoria da uniformização jamais perecerá!”. Ele é vergonhosamente ingênuo em alguns aspectos. Quando L me disse que Courant ${ }^{6}$ iria solicitar um livro meu para publicação, ele apresentou uma oferta (de modo meio ou inteiramente jocoso) para um livro na sua série, que rivaliza com a de Courant.

Encontrei um simpático estudante suíço da Escola Superior Técnica de Dresde (Dresdner Technische Hochschule) no trem que saía de Leipzig. Ele falava muito bem o inglês e tivemos uma animada conversação em ambas as línguas. Tomamos o café da manhã juntos no carro-restaurante quando saíamos de Frankfurt. Em uma mesa próxima da nossa, notei um rosto estranhamente familiar e disse ao meu companheiro, “como meu chapéu se não for Einstein!". Depois do café da manhã, decidi procurá-lo, tendo em vista sua amizade com Lichtenstein, de mesma profissão, e o fato de que tinha sido apresentado a ele nos Estados Unidos. Eu o encontrei em um compartimento de terceira classe e, de fato, era Einstein. Quando lhe disse que eu era um matemático, ele começou a perguntar-me sobre a minha linha. Ficou bem impressionado com o meu pequeno trabalho ("light stuff"). Então, começou a falar-me da sua redução da gravitação e das equações de Maxwell a um único problema de minimização. Esse é um trabalho inteiramente novo, ainda não publicado, e escrito faz três semanas. É uma realização da mesma magnitude que as das teorias da relatividade especial e geral. As aproximações de segunda ordem e de ordem superior não estão desenvolvidas ainda, e prometem ser diabolicamente difíceis, mas ele tem uma vaga esperança de que elas possam conter o segredo do elétron e da teoria quântica. Entretanto, ele nada tem feito nessa direção.

Eu me retirei depois de meia hora, porque não queria importunar o pobre homem, que deve andar pressionado até a morte com tantos idiotas que tomam seu tempo. Em Basiléia, entretanto, eu o vi saindo do trem. Aconteceu que íamos ambos para Genebra e eu tinha que adquirir a passagem. Ele me disse para procurá-lo no trem ou, pelo menos, demonstrou desejo de continuar com a minha companhia. Enquanto eu iria de terceira classe, ele viajaria de segunda. Explicou-me que ia participar de uma reunião do comitê para a colaboração científica da Liga das Nações em Genebra e, como disse ingenuamente, queria causar uma boa impressão ao comitê, quando descesse do trem. Contudo, mudou-se comigo para o compartimento de terceira classe e não quis ouvir minha sugestão de eu me mudar para a segunda classe. De Basiléia até Genebra, tivemos cerca de cinco horas e meia de contínua conversação sobre todos os assuntos imagináveis; e eu não forcei minha presença ao longo da conversa. Ele falou do comitê 
da Liga das Nações, disse que não valia grande coisa mas que abandoná-lo seria um vergonhoso passo em falso. Disse que cinco horas de discussão o enfadavam até a extinção, mas que valia a pena pela possibilidade de encontrar Madame Curie, Hardy (penso) e outros eminentes cientistas. Parecia muito pessimista sobre as perspectivas de reaproximação científica na Europa: disse que os alemães tinham sido excluídos por tanto tempo que também eles se tinham desinteressado. Ele sentia, contudo, que uma reaproximação entre as nações ou outra guerra mundial eram as únicas coisas possíveis de acontecer. Não concorda com Russell ${ }^{\mathbf{8}}$ de que outra guerra mundial será o fim da civilização, mas acha que, nesse caso, a liderança da civilização passará para a América e, posteriormente, para a Ásia. Ele acha que o nível educacional geral nos Estados Unidos é pobre, mas que entre nós existem grandes centros educacionais e que trabalhos muito bons estão sendo feitos. Ele tem grandes esperanças nos Estados Unidos. Ele está muito interessado na situação da Rússia, é simpático ao socialismo, mas está desgostoso com a intolerância e o sistema de espionagem dos bolcheviques.

Vive há muito tempo na Suíça e gosta muito dos suíços. Ele prefere o espírito livre desse povo ao rígido espírito alemão. É muito inconformista (umbanzenhaft), mas diz que é difícil ser inconformista, em um ambiente conformista (banzenhaft) (nota: um Banze é um professor alemão do tipo Münsterberg). ${ }^{9}$ Ele acha que é necessário proteger seu tempo de intrusões indevidas. Nos últimos anos, viaja por todo o mundo, mas agora quer reduzir essas viagens para ter mais tempo para trabalhar.

Ele lamenta a existência do nacionalismo extremado na Alemanha, mas assevera que tal coisa de fato existe. Ao mesmo tempo, ficou chocado quando eu lhe falei dos versos de vingança que eu havia visto nas hospedarias e à venda em livrarias. Ele não é anti-francês. Eu nunca encontrei um homem com a mente tão sã e tão sóbria.

Discutiu comigo as possibilidades dos métodos de equações integrais em relatividade e me perguntou sobre várias questões. Ficou muito impressionado com a definição de Phil para as funções potenciais. Falou-me de um trabalho que ele próprio fez, e que está estreitamente relacionado a um certo trabalho de Rado ${ }^{10}$ sobre superfícies minimais, o qual eu tinha ouvido um estudante apresentar no seminário de L em Leipzig, e que ainda não foi publicado. Ele me explicou seu ponto de vista sobre a teoria das transformações paralelas de Levi-Civita. ${ }^{\mathbf{1 1}}$ Eu compreendi, a partir da explicação que ele me apresentou, o significado estatístico da segunda lei da termodinâmica. Ele me explicou que o universo como um $\underline{\text { todo }}^{\mathbf{1 2}}$ não está próximo de uma posição de equilíbrio estatístico, mas que há uma tendência definida para essa posição, como se tivesse existido uma criação. Ele disse que o tratamento que Planck deu à questão está totalmente errado, e considera que entender corretamente essa questão é muito mais difícil que entender corretamente a relatividade. 
Considera o estado presente de confusão na ciência como temporário, e que ele é devido à ausência de idéias de real destaque. Lamenta a inundação da literatura com artigos imaturos, sem idéias, e enfatiza a forma na apresentação. Nisso, ele é um mestre.

Tem um amor imenso pelas belezas da natureza; esteve continuamente mostrando-me os efeitos das nuvens sobre os lagos de Biel e Neufchatel. Gosta das partes da Suíça mais quietas, menos infestadas de turistas, como o Jura. Ele gosta de florestas e de paisagens como as da nossa Nova Inglaterra.

Está muito interessado em engenharia; trabalhou sete anos no escritório de patentes suíço. As novas locomotivas excitaram sua intensa curiosidade.

Pessoalmente é simples, direto, sem afetação e charmoso. 0 mais casual dos observadores ficará sensibilizado pela sua enorme energia intelectual, sua visão clara e seu sentido de realidade física, e pelo seu entusiasmo. Ele tem consciência da posição especial que ocupa, mas de modo algum é vaidoso. Não espera que a relatividade, na sua presente forma, dure muitas décadas, e espera que outros trabalhos logo irão além dela. Sobre a teoria quântica, para a qual deu grandes contribuições, ele está muito insatisfeito. Julga os outros cientistas generosamente, não por uma escala de valores excessivamente extensa. Ele espera que alguém faça uma contribuição seminal no futuro não distante conseguindo esclarecer a teoria da radiação na teoria quântica.

Por favor, não pense que tive um comportamento intrusivo na presença dele. Eu fui respeitoso, mas não o tratei como o Senhor Todo-Poderoso, porque posso imaginar que ele detestaria esse tipo de tratamento. Nós nos separamos no melhor dos termos. Eu o agradeci pela oportunidade que me havia propiciado, e ele me colocou à vontade e considerou nossa conversação muito agradável (ganze nett). Nós conversamos em alemão, evidentemente, pois ele não fala inglês (embora fale francês, italiano e algum espanhol).

Já batemos papo o suficiente, e dado que estou no final da minha terceira folha de papel, concluo perguntando por notícias de Caroll no meio dos jaguares e dos mosquitos.

Do irmão que te ama,

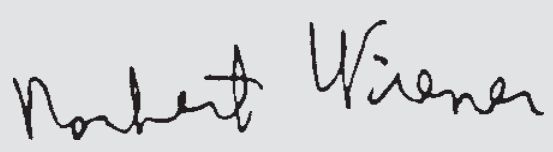




\section{Notas À carta de Wiener A sua irmã Bertha sobre o encontro com Einstein}

\section{Notas}

1 Bertha Wiener (Dodge) era a irmã mais nova de Norbert Wiener. Tinha então 23 anos, e estudava Química no MIT. Ela havia visitado a França e a Alemanha no ano anterior em companhia de Wiener. Os irmãos Norbert e Bertha foram educados tendo o alemão como segunda língua. Leo Wiener, o pai, era alemão, e ensinava línguas e literatura eslavas na Universidade de Harvard (cf. Wiener, 1956, p. 90).

2 Elie Cartan (1869-1951), matemático francês. Ver o texto de apresentação para maiores detalhes.

3 Quando Wiener ainda estava em Leipzig, no sábado precedente.

4 L é Leon Lichtenstein, matemático alemão, e então diretor da Faculdade de Ciências da Universidade de Leipzig. Lichtenstein era primo de Wiener, mas eles só tomaram consciência do laço de parentesco em 1924, quando Wiener e Bertha visitaram Lichtenstein pela primeira vez (cf. Wiener, 1956, p. 94).

5 Paul Koebe (1882-1945), matemático alemão, trabalhou sobre a teoria das funções complexas, com resultados importantes sobre a uniformização das superfícies de Riemann, um assunto explorado anteriormente por Felix Klein e Henri Poincaré. Professor em Iena, em 1914, voltou definitivamente para Leipzig, onde tinha iniciado sua carreira, em 1926.

6 Richard Courant (1888-1972), matemático alemão da Universidade de Göttingen, obrigado pelo regime nazista a exilar-se nos Estados Unidos em 1933. Era especialista em análise, teoria das funções e física matemática. Redigiu com David Hilbert (1862-1943), matemático alemão muito conhecido, um livro que ficou famoso, Methoden der mathematischen Physik (1924).

7 Marie Curie (1867-1934), física francesa de origem polonesa, pioneira da radioatividade, grande amiga de Einstein. Godfrey Harold Hardy (1877-1967), matemático inglês, especialista de análise e da teoria dos números, produziu trabalhos fundamentais na teoria das séries e das equações integrais; colaborou com o matemático inglês J. E. Littlewood (1885-1977) e com o matemático indiano Ramanujan (1887-1920), sobre o qual escreveu uma biografia renomada.

8 Bertrand Russell (1872-1970), matemático, lógico e filósofo inglês, também muito inconformista e de idéias progressistas, como Einstein. Ele e Einstein lançarão, alguns anos depois do fim da Segunda Guerra Mundial, o apelo Einstein-Russell contra a corrida das armas nucleares.

9 A nota está no manuscrito. Provavelmente Wiener refere-se a Hugo Münsterberg, psicólogo alemão, aluno de Wilhelm Wundt, que se transferiu para a Universidade de Harvard a convite de William James. Ele parece aqui estar sendo tomado tanto por Norbert Wiener quanto por sua irmã Bertha como expressão da autoridade atribuída aos professores universitários alemães.

10 Tibor Rado (1895-1965), matemático húngaro e depois norte-americano, especialista em análise e, particularmente, em superfícies minimais limitadas por um contorno dado ("problema de Plateau").

11 Tullio Levi-Civita (1873-1941), físico e matemático italiano, inventor, com Gregorio Ricci-Curbastro (1853-1925), matemático italiano, do cálculo tensorial (1900). Este assunto está relacionado com as tentativas de Einstein na direção de uma teoria unificada dos campos contínuos, gravitacional e eletromagnético.

$12 \mathrm{O}$ termo foi sublinhado por Wiener. Este assunto liga-se à cosmologia, como comentamos na apresentação.

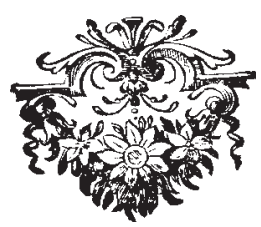

